\title{
ENTREVISTA: PROFESSOR HELDER A. M. DE MACEDO
}

\section{INTERVIEW: PROFESSOR HELDER A. M. DE MACEDO}

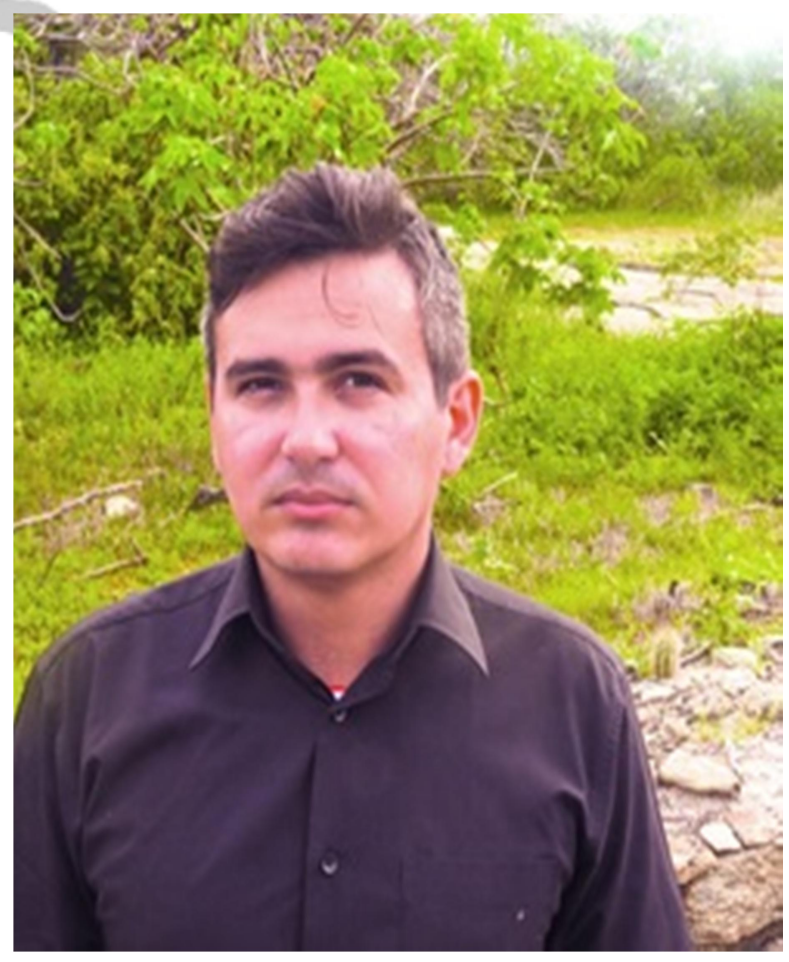

${ }^{1}$ Departamento de História, Universidade Federal do Rio Grande do Norte, UFRN.
Historiador e professor de História. Atualmente é Professor do Departamento de História do CERES, da Universidade Federal do Rio Grande do Norte, lecionando no Campus de Caicó. Atua como Professor Permanente do Programa de Pós-Graduação em História do CERES-UFRN/Mestrado em História dos Sertões e como Colaborador do Programa de PósGraduação em História do CCHLAUFRN/Mestrado em História e Espaços. É participante da Rede de Grupos de Pesquisa Escravidão e Mestiçagens. Seus interesses de pesquisa estão ligados à História dos Sertões, História sóciocultural da América portuguesa, índios, negros, mestiçagens, escravidão, acervos e 
patrimônio cultural.

Clio: Considerando que o Senhor é natural do município de Carnaúba dos Dantas-RN, como se deram os primeiros contatos com os vestígios e sítios arqueológicos e a pesquisa desenvolvida na área arqueológica do Seridó?

Professor Helder Macedo: Desde pequeno eu tive curiosidade por saber mais sobre a minha história familiar e, assim, comecei a fazer pesquisas aos 11 anos, em busca de montar minha árvore genealógica. Isso levou-me a um interesse, também, pela História Local - e, mais tarde, pela História Regional. Cada vez que

\section{Na Biblioteca Pública Donatilla}

Dantas, que foi a minha internet na infância e adolescência, li alguns exemplares da revista Clio, (...) a partir dos quais percebi que havia, naquela altura, uma trajetória de pesquisa científica que beirava os vinte anos, em relação a sítios arqueológicos no Seridó eu me aproximava mais das narrativas sobre o passado de Carnaúba dos Dantas, por meio de documentos manuscritos, de bibliografia e de entrevistas, sobretudo em se tratando do que a oralidade me transmitia, apareciam referências a "pinturas dos índios", "casas dos caboclos", "pinturas rupestres".

Isso me fascinou, levando-me a, na metade dos anos de 1990, procurar mais informações sobre o assunto. Na Biblioteca Pública Donatilla Dantas, que foi a minha internet na infância e adolescência, li alguns exemplares da revista Clio, do Programa de Pós-Graduação em História da Universidade Federal de Pernambuco 
(UFPE), a partir dos quais percebi que havia, naquela altura, uma trajetória de pesquisa científica que beirava os vinte anos, em relação a sítios arqueológicos no Seridó, especialmente, em Carnaúba dos Dantas e em Parelhas. Na mesma biblioteca, lendo as correspondências de Donatilla Dantas com pessoas da minha cidade, confirmei o que já sabia por ouvir dizer de familiares, em entrevistas: que

No ano de 1995, (...) foi realizada, na minha cidade, a Exposição José de Azevêdo Dantas, em homenagem a esse pioneiro das pesquisas arqueológicas no Seridó paraibano e potiguar, cuja vernissage contou com o lançamento do livro, póstumo, Indícios de uma Civilização Antiquíssima um tio-trisavô, José de Azevêdo Dantas (1890-1929) havia feito um levantamento de lugares com inscrições rupestres no que hoje é o município de Carnaúba dos Dantas. E que o manuscrito deixado por esse meu tio, depositado pelo meu trisavô Mamede Azevêdo, após sua morte, no Instituto Histórico e Geográfico Paraibano (IHGP), em João Pessoa-PB, havia sido um dos motivadores da vinda, ao Seridó, da equipe do Núcleo de Estudos Arqueológicos (NEA) da UFPE, então, coordenado pela professora Gabriela Martin.

Por essa mesma época, metade dos anos 1990, visitei dois sítios arqueológicos que me deixaram perplexo, pela sua existência e pela permanência, ainda, dos vestígios rupestres, denotando uma presença muito antiga de sociedades humanas 
por aquelas bandas: o sítio Pedra do Alexandre, popularmente conhecida como "Pedra dos Índios" ou "Pedra do Índio" e o sítio do Pote, ambos, nas circunvizinhanças do Povoado Ermo.

Na infância, eu já tinha visto as pinturas de um sítio arqueológico na Volta do Rio, na beira do rio Carnaúba, mas, de maneira muito rápida, sem ter algum conteúdo sobre as pesquisas em torno desse patrimônio cultural. Depois dos sítios arqueológico Pedra do Alexandre e Pote, em companhia de José Martins da Silva (1960-2000), conhecido como Deca de Valdemar de Chica Pé-de-Pão, visitei e conheci o rico acervo do Riacho do Bojo e do Riacho do Olho d'Água, notadamente, os sítios Casa Santa e Grota Funda, situado, este, na Cachoeira dos Fundões.

No ano de 1995, fruto de um convênio de cooperação técnico-científica entre o NEA-UFPE e a Prefeitura Municipal de Carnaúba dos Dantas, foi realizada, na minha cidade, a Exposição José de Azevêdo Dantas, em homenagem a esse pioneiro das pesquisas arqueológicas no Seridó paraibano e potiguar, cuja vernissage contou com o lançamento do livro, póstumo, Indícios de uma Civilização Antiquíssima, do referido pesquisador, publicado por iniciativa da professora Gabriela Martin.

Daí em diante, me voluntariei para acompanhar a equipe do NEA-UFPE em algumas das pesquisas realizadas em Carnaúba dos Dantas, entre 1995 e, aproximadamente, os anos 2000. Foram anos de muito aprendizado, com as 
professoras Gabriela Martin, Ana Nascimento, Cláudia Alves, Suely Luna e, também, com os estudantes de graduação e bolsistas.

Clio: Além desta exposição referida, aconteceram outros dois eventos de socialização das pesquisas arqueológicas e educação patrimonial, realizados pela equipe da Fundação Seridó: "A Pré-história do Seridó" e "Dez mil anos de arte no Seridó". Considerando que ocorreram durante o período de sua participação como membro voluntário das equipes de arqueologia, de que modo avalia o impacto dessas ações na gestão do patrimônio arqueológico do município de Carnaúba dos Dantas?

Professor Helder Macedo: Considero que ambas as iniciativas foram extremamente positivas, tanto para a gestão do patrimônio arqueológico em Carnaúba dos Dantas, quanto para o seu reconhecimento por parte da população enquanto tal, que pode ser encarado como um dos vértices onde se apoia a gestão. Participei, como voluntário do NEA, da primeira, A Pré-História no Seridó, realizada em 1996, no salão do Centro de Atividades Recreativas (CENAR), tanto como aluno inscrito em oficinas de arte ministradas por professores e alunos da UFPE, quanto, na montagem da exposição.

Esta, em minha avaliação, foi um marco, pois, representou o primeiro retorno, a Carnaúba dos Dantas, de parte dos restos ósseos escavados no sítio Pedra do Alexandre, que ficaram expostos em uma vitrine de acrílico, para apreciação dos visitantes, durante o tempo em que durou a exposição. A reprodução de painéis de sítios arqueológicos de Carnaúba dos Dantas e Parelhas, bem como, a 
reconstrução de um abrigo sob rocha, deram um tom especial a essa iniciativa, que, com a visitação de dezenas de turmas da cidade e de municípios circunvizinhos, contribuiu para que uma geração de crianças e jovens pudesse saber que aquelas pinturas reproduzidas nos painéis eram parte do legado deixado pelas pessoas que habitaram essa região há, pelo menos, dez mil anos antes do presente.

Ambas as exposições (...) tiveram a curadoria do arqueólogo Plínio Victor, que traduziu na proposta, o desejo de que as comunidades que moravam nas regiões detentoras de sítios arqueológicos pudessem aperceber-se e apropriar-se da importância desse patrimônio milenar.
Não posso deixar de lembrar que parte dessa exposição foi também feita com os resultados das oficinas de arte, integrando pequenos painéis produzidos pelos alunos locais, partícipes, assim, da própria filosofia da montagem da exposição. Em 1997 ocorreu a outra exposição, Dez mil anos de arte no Seridó, que foi, igualmente, outro marco nas ações de Educação Patrimonial realizadas pela Fundação Seridó, na região, junto ao NEA-UFPE. Como parte preparatória, artistas visuais provenientes do Estado de Pernambuco foram trazidos a diversas cidades do Seridó, onde realizaram oficinas de arte, com alunos das localidades, tendo como foco a valorização do patrimônio arqueológico da região. 
Os painéis resultantes dessas oficinas juntaram-se a outros, monumentais, que foram distribuídos em toda a quadra do Centro Educacional José Augusto (CEJA), em Caicó, capital da região do Seridó, compondo a maior exposição ligada à arte rupestre que eu já tive oportunidade de visitar, em minha vida. Na vernissage da exposição houve o lançamento, inclusive, de uma das edições do livro PréHistória do Nordeste do Brasil, da professora Gabriela Martin, a quem se deve a liderança das pesquisas do NEA-UFPE nessa época e direção da Fundação Seridó. Ambas as exposições, a de Carnaúba dos Dantas e a de Caicó, tiveram a curadoria do arqueólogo Plínio Victor, que traduziu na proposta, o desejo de que as comunidades que moravam nas regiões detentoras de sítios arqueológicos pudessem aperceber-se e apropriar-se da importância desse patrimônio milenar.

\section{Clio: Como essas experiências influenciaram suas escolhas e desenvolvimento profissional, como pesquisador em História?}

Professor Helder Macedo: Em princípio, a partir do contato e do aprendizado que tive junto ao NEA, tive uma tendência a seguir carreira acadêmica e profissional no campo da Arqueologia. Todavia, ao entrar no Curso de História do Centro de Ensino Superior do Seridó (CERES), da Universidade Federal do Rio Grande do Norte (UFRN), Campus de Caicó, gradativamente fui firmando minhas raízes nos domínios de Clio. Atuei como bolsista de iniciação científica, sob orientação do professor Muirakytan Kennedy de Macêdo, de 1999 a 2002, em planos de trabalho atrelados a projetos que objetivavam estudar a criminalidade 
escrava, o cotidiano urbano e a demografia histórica, para o recorte do Sertão do Seridó ou da Cidade do Príncipe (atualmente, Caicó), entre os períodos colonial e imperial. Fruto dessa passagem pela oficina do historiador, sob os cuidados do já citado mestre, aos poucos fui desenhando a intenção de pesquisa a desenvolver no trabalho monográfico do curso - à época, com as habilitações de Licenciatura e Bacharelado. Incomodava-me, desde o período em que me interessei pela História

No Ensino Primário, eu havia aprendido (...) que os índios Kariri tinham sido os primeiros habitantes de Carnaúba dos Dantas; mas, depois disso, já se falava em Caetano Dantas Corrêa como "fundador" do município, tese que, anos mais tarde, vim a desconstruir. Como se os nativos "desaparecessem" após a chegada dessa pessoa, o "fundador"
Local e Regional, uma ausência de menções, em livros, sobre os indígenas que haviam habitado o espaço e que, posteriormente à chegada dos europeus e luso-brasílicos, foi chamado de Seridó, onde eu morava. $\mathrm{Na}$ escola, por exemplo, no Ensino Primário, eu haviaaprendido, com minhas

professoras, que os índios Kariri tinham sido os primeiros habitantes de Carnaúba dos Dantas, mas, depois disso, já se falava em Caetano Dantas Corrêa como "fundador" do município, tese que, anos mais tarde, vim a desconstruir. Como se os nativos "desaparecessem" após a chegada dessa pessoa, o "fundador". Por esse mesmo tempo, numa ida ao sítio Volta do Rio, fiquei cheio de dúvidas quando, num banho de poço, um primo me apontou um lugar, na margem do rio, onde 
havia "pinturas dos índios". Era estranho, ouvir aquilo, considerando que, nos bancos escolares, não havia referência à presença indígena, quem dirá, a seus vestígios. Encontrei terreno fértil para questionar esse suposto "desaparecimento" indígena ao ler os escritos de Sinval Costa, dom José Adelino Dantas e Olavo de Medeiros Filho - os dois últimos, em especial, as suas últimas publicações, antes de falecerem.

As pistas deixadas por esses historiadores eruditos me levaram aos mesmos conjuntos documentais que estava usando na Iniciação Científica, as fontes paroquiais. Nessas fontes históricas, encontrei a população indígena, cristianizada, a partir do século XVIII, participando de ritos cristãos (batizado, casamento, óbito), na matriz e templos da Freguesia do Seridó, ao lado dos brancos, pretos e mestiços, sendo diferenciada do restante da população com as qualidades de "índio" ou "tapuia".

Desse exame e análise das fontes surgiu a monografia que defendi em 2002, Vivências índias, mundos mestiços: relações interétnicas na Freguesia da Gloriosa Senhora Santa Ana do Seridó entre o final do século XVIII e início do século XIX, sob orientação do Professor Muirakytan Macêdo. Posso admitir, então, que, embora não tenha trilhado o caminho da Arqueologia, não deixei de dialogar com temas caros a este último campo, sobretudo, ao tratar da realidade dos povos nativos, após o período de conquista e colonização dos sertões. Ressalto, também, como mencionado anteriormente, que os vestígios 
arqueológicos de Carnaúba dos Dantas e sua existência atrelada à ideia de legado indígena foram um ponto importante para a construção da problemática que gerou o estudo monográfico. Parte desse estudo foi publicado, como capítulo de livro, na obra Repensando a História do Rio Grande do Norte (2007), organizada pelo professor Almir de Carvalho Bueno, com o título de "História Indígena no Seridó (séc. XVI-XX)".

Clio: Como foi o seu percurso, em termos profissionais e acadêmicos, em nível de pós-graduação?

Professor Helder Macedo: No mesmo ano em que concluí a graduação, fiz seleção para o Mestrado em História na UFPE. Submeti um projeto que, hoje, considero, por demais,

Nessas fontes históricas, encontrei a população indígena, cristianizada, a partir do século XVIII, participando de ritos cristãos (batizado, casamento, óbito), na matriz e templos da Freguesia do Seridó, ao lado dos brancos, pretos e mestiços faraônico (e insustentável, a bem da verdade): ele propunha estudar as sociabilidades entre índios e não índios, no Seridó, após a Guerra dos Bárbaros (séculos XVII-XVIII), mas, principiava com uma revisão das pesquisas sobre as ocupações pré-históricas na região. Fui aprovado em todas as etapas, mas, na entrevista, o resultado não poderia ser diferente: fui reprovado. 
Tomei como lição essa desaprovação e retornei ao Seridó, onde, pouco tempo depois, prestei seleção simplificada para Professor Substituto, no antigo Departamento de História e Geografia, do CERES-UFRN, Campus de Caicó.

Fiquei aprovado em segunda colocação, o que permitiu que o Departamento fizesse uma convocação, a posteriori, em função de carência de pessoal docente. Refiro-me, aqui, dentre outras carências, àquela provocada pelo afastamento do professor Muirakytan Macêdo para cursar o doutorado em Ciências Sociais, no

Investiguei as transformações que a ocidentalização acarretou, em dois âmbitos: inicialmente, nos espaços ditos sertanejos, de um "Sertam dos Tapuias" até um sertão colonial e cristão, em termos do gerenciamento do território; e, também, as modificações que esse processo de imposição de um modo de vida ocidental trouxe para as populações indígenas
Campus Central da UFRN, em Natal. No rol de disciplinas que foram colocadas para eu ministrar, estavam aquelas da área de História do Rio Grande do Norte, anteriormente, sob supervisão do meu mestre.

Em função da minha convivência anterior, junto ao NEA, e de afinidade, o Departamento me deixou, sob responsabilidade, também, a ministração de disciplinas como Pré-História e Arqueologia. Essa minha passagem pelo Ensino Superior, como professor substituto, se deu entre os anos de 2003 e 2005, sendo 


\section{Clio Arqueológica 2020, V35N3, p.1-17, MAFRA

interrompida pela minha aprovação, simultaneamente, nos processos seletivos de mestrado da UFPE e da UFRN, recém criado.

Também fui aprovado, na mesma época, na primeira fase da seleção de mestrado da Universidade Federal do Ceará (UFC), mas, a sobreposição de datas com os outros processos seletivos (UFRN, sobretudo) me impediu de continuar com as etapas. No mesmo período em que atuei como Professor Substituto, na UFRN, fiz o curso de pós-graduação lato sensu de Patrimônio Histórico-Cultural e Turismo, onde defendi, ao final, a monografia Inventário do Patrimônio Arqueológico de Carnaúba dos Dantas (2005), sob orientação do Professor Muiraytan Macêdo.

Esse inventário apresentou um balanço das pesquisas realizadas até 2005, no referido recorte espacial; bem como, listou a existência de sítios arqueológicos com pinturas e gravuras rupestres, documentados por meio de registro fotográfico.

O trabalho de inventariação, não posso furtar-me a dizer, foi fruto de uma experiência com o Grupo de Estudos em Patrimônio e Arqueologia do Seridó (GEPS), que desenvolvi, em Carnaúba dos Dantas, com jovens, no mesmo período. Fruto dessa monografia, publiquei alguns artigos e o seu conteúdo foi desdobrado em dois livros: Patrimônio arqueológico em Carnaúba dos Dantas: pesquisas realizadas entre 1924 e 2005 (2009), premiado no Projeto Rota Batida (Fundação Vingt-Un Rosado e Petrobras) e Patrimônio Arqueológico do Seridó: sítios rupestres em Carnaúba dos Dantas (2011). Em termos da pós-graduação 


\section{Clio Arqueológica 2020, V35N3, p.1-17, MAFRA DOI: 10.20891/clio. V35N3p1-17}

stricto sensu, optei por realizar o Mestrado em História na UFRN, no curso recém criado, com área de concentração em História e Espaços, processo que decorreu de 2005 a 2007. Defendi, ao final, a dissertação Ocidentalização, territórios e populações indígenas no sertão da Capitania do Rio Grande, orientada pela Professora Fátima Martins Lopes.

Nesse estudo, um aprofundamento da monografia da graduação, investiguei as transformações que a ocidentalização acarretou, em dois âmbitos: inicialmente, nos espaços ditos sertanejos, de um "Sertam dos Tapuias" até um sertão colonial e cristão, em termos do gerenciamento do território; e, também, as modificações que esse processo de imposição de um modo de vida ocidental trouxe para as populações indígenas que aí habitavam, mormente, a sua convivência no seio do Cristianismo, após a Guerra dos Bárbaros e a implementação de arraiais, povoações, freguesias e vila, no Seridó.

Modificações essas que foram posteriores a processos extremamente violentos envolvendo mortes, fugas, escravizações e, dentre outros, aldeamentos, como assinalaram estudos anteriores de Idalina Pires, Fátima Lopes, Pedro Puntoni e Ricardo Medeiros. A dissertação de mestrado defendida foi uma das vencedoras em um edital interno da UFRN e teve a sua publicação, no formato de livro, em 2011, com o título Populações indígenas no sertão do Rio Grande do Norte: história e mestiçagens, pela EDUFRN. De 2005 a 2008, atuei como docente em algumas universidades e faculdades (Universidade Potiguar, Universidade do Vale 
do Acaraú, Faculdade do Seridó, citando algumas) e, também tive uma passagem, como assessor técnico, na Fundação de Apoio à Pesquisa do Estado do Rio Grande do Norte (FAPERN), em Natal.

Após esse período, submeti projeto à seleção do Doutorado em História na UFPE e, após aprovação, ingressei na pós-graduação em 2009, tendo defendido a tese em 2013, sob orientação da Professora Tanya Maria Pires Brandão. Considero essa tese a culminância de um processo de pesquisa que iniciou na graduação, onde, pouco a pouco, fui me apercebendo que, embora estudasse, ora populações pretas, ora, indígenas, era elevado, demograficamente, nos Sertões do Seridó, o número de pessoas "mestiças", isto é, fruto de misturas, como pardos, mulatos e cabras.

Esse foi o mote para o estudo proposto, onde investiguei as "genealogias mestiças", conceito que desenvolvi na tese, de três famílias situadas no Seridó entre a Colônia e o Império: a do crioulo forro Nicolau Mendes da Cruz, do sítio São José; a do preto forro Feliciano da Rocha de Vasconcelos, do sítio Barrentas; e a do pardo Manuel Esteves Andrade e seus sobrinhos Francisco e Antonio Pereira, do sítio Saco. As genealogias mestiças constituídas a partir da descendência desses três patriarcas agregaram pessoas de diferentes qualidades (pretos, brancos, índios, pardos) e condições (livres e escravos). 
No caso daquela principiada por Nicolau Mendes, posso afirmar, com base na documentação histórica compulsada, que já estava instalada pelos sertões antes mesmo das supostas famílias tradicionais (Araújo Pereira, Dantas Corrêa, por exemplo) construírem suas fazendas de criação de gado e parentelas. Fruto dessa tese, que em breve será publicada no formato de livro, desenvolvo pesquisas até os dias de hoje.

Clio: Com a implantação do Programa de Pós-Graduação em História, com área de concentração em História dos Sertões, na UFRN, como a Arqueologia do Seridó tem contribuído no desenvolvimento das linhas de pesquisa propostas?

Professor Helder Macedo: O Mestrado em História dos Sertões, a partir de sua aprovação, em 2018, e implementação, em 2019, tem como uma de suas linhas de pesquisa Cultura material, sociedade e poder nos sertões. Considerando a historicidade do conceito que conforma a área de concentração - o de sertão ou sertões - e sua disseminação a partir do período moderno, com as navegações portuguesas para além da Europa, os estudos de Arqueologia Histórica e aqueles que se ocupam de analisar os estudos já realizados sobre as ocupações préhistóricas, em sua continuidade até o período de contato com o mundo ocidental, são, especialmente, objeto de interesse da referida linha de pesquisa.

Uma das dimensões dessa linha, a da História da Cultura Material, leva em conta o conceito de cultura material, ou materialidade, inclusive, como uma tecedura no entorno das memórias e dos esquecimentos, sob os quais se sustentam, também, 
as temáticas ligadas ao Patrimônio Cultural. As temáticas que a linha abriga são aquelas que, tomando os sertões enquanto recorte espacial, incidem sobre a arqueologia das ocupações dos espaços sertanejos, das apropriações territoriais e da diáspora africana; etnicidade, cultura material e a produção de artefatos de diferentes grupos em suas vivências nos sertões; patrimônio cultural e educação nos sertões.

Isso garante a agregação de importantes pesquisas já realizadas no Seridó, como a sua, em especial, Fábio, que resultou na tese de doutorado Os Sítios Arqueológicos Furna do Umbuzeiro e Baixa do Umbuzeiro: caracterização de um padrão de assentamento na área arqueológica do Seridó (Carnaúba dos Dantas$R N)$ (2010), onde você explorou a possibilidade de similitude entre a cultura

As temáticas (...) incidem sobre a arqueologia das ocupações dos espaços sertanejos, das apropriações territoriais e da diáspora africana; etnicidade, cultura material e a produção de artefatos de diferentes grupos em suas vivências nos sertões material registrada em sítios habitacionais - da área arqueológica referida - com aquela referenciada na documentação etnohistórica sobre os Tarairiú, populações indígenas que entraram em contato com holandeses, portugueses e luso-brasílicos, a partir do século XVII; o que poderia, em nível de hipótese, ressoar em uma continuidade das práticas culturais desses grupos até o momento da 


\section{Clio Arqueológica 2020, V35N3, p.1-17, MAFRA}

conquista e colonização, no período colonial.

Acrescento, também, as pesquisas do Professor Abrahão Sanderson Nunes Fernandes da Silva, a partir de 2017, com foco em dois projetos: Arqueologia em casas de fazendas da região Seridó: uma (Inter)relação entre espacialidades, temporalidades e sociabilidades no sertão do Rio Grande do Norte e Arqueologia em casas de fazenda na região Seridó: espacialidades, temporalidades e sociabilidades no sertão do Rio Grande do Norte. Ambos os projetos têm proporcionado importantes frutos e reflexões sobre o campo da Arqueologia Histórica nos Sertões do Seridó, em interface com os estudos de História Colonial produzidos por Muirakytan Kennedy de Macêdo e, dentre outros, os meus.

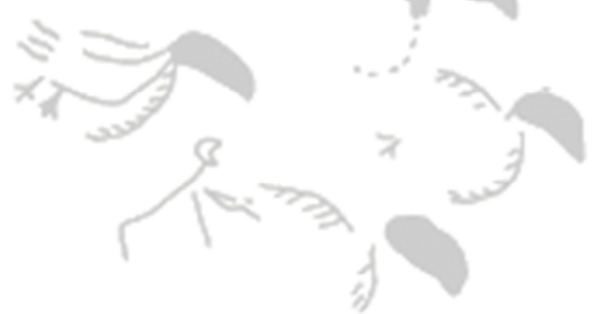

